\title{
Investigation on Durability Performance in Early Aged High-Performance Concrete Containing GGBFS and FA
}

\author{
Seung-Yup Jang, ${ }^{1}$ Subbiah Karthick, ${ }^{2}$ and Seung-Jun Kwon ${ }^{3}$ \\ ${ }^{1}$ Korea Railroad Research Institute, Suwon, Republic of Korea \\ ${ }^{2}$ Innovative Durable Building and Infrastructure Research Center, Hanyang University, 55 Hanyangdaehak-ro, Sangrok-gu, \\ Ansan-si, Gyeonggi-do, Republic of Korea \\ ${ }^{3}$ Department of Civil and Environmental Engineering, Hannam University, 133 Ojeong-ding, Daejeon 306-791, Republic of Korea
}

Correspondence should be addressed to Seung-Jun Kwon; jjuni98@hannam.ac.kr

Received 30 December 2016; Accepted 23 February 2017; Published 8 March 2017

Academic Editor: Xiao-Jian Gao

Copyright (C) 2017 Seung-Yup Jang et al. This is an open access article distributed under the Creative Commons Attribution License, which permits unrestricted use, distribution, and reproduction in any medium, provided the original work is properly cited.

\begin{abstract}
The significance of concrete durability increases since RC (Reinforced Concrete) structures undergo degradation due to aggressive environmental conditions, which affects structural safety and serviceability. Steel corrosion is the major cause for the unexpected failure of RC structures. The main cause for the corrosion initiation is the ingress of chloride ions prevailing in the environment. Hence quantitative evaluation of chloride diffusion becomes very important to obtain a chloride diffusion coefficient and resistance to chloride ion intrusion. In the present investigation, $15 \mathrm{mix}$ proportions with 3 water-to-binder ratios $(0.37,0.42$, and 0.47$)$ and 3 replacement ratios $(0,30$, and 50\%) were prepared for HPC (high-performance concrete) with fly-ash and ground granulated blast furnace slag. Chloride diffusion coefficient was measured under nonstationary condition. In order to evaluate the microstructure characteristics, porosity through MIP was also measured. The results of compressive strength, chloride diffusion, and porosity are compared with electrical charges. This paper deals with the results of the concrete samples exposed for only 2 months, but it is a part of the total test plan for 100 years. From the work, time-dependent diffusion coefficients in HPC and the key parameters for durability design are proposed.
\end{abstract}

\section{Introduction}

Reinforced concrete (RC) structures are an economical and versatile construction material in civil infrastructure such as bridges, buildings, and nuclear reactors, and involve major construction to the tune of millions of dollars [1,2]. However, the long term durability and service life of RC structures are one of the major problems faced by the construction industry for the past few decades [3]. The durability of reinforced concrete is largely affected by the migration of aggressive ions (chloride and sulphate) via capillary absorption and hydrostatic pressure of cementitious matrix. The ions reach the reinforced rebar and destroy the passive film $[4,5]$ subsequently corroding the steel. Chloride induced corrosion of RC structure has become a major problem worldwide [68], especially in buildings, bridges, parking decks, tunnels, and other buildings exposed to seawater or deicing salts. As a result of this deterioration of the RC structure, the repair costs nowadays constitute a major part of spending on infrastructure. Further, corrosion of steel does not only damage the RC structure but also causes safety concerns.

Corrosion of steel in the RC structure can be mitigated by adopting various preventive measures, namely, cathodic protection, using corrosion inhibitors, coating to steel rebar, coating to concrete, using blended cement, and realkalization of concrete [9-14]. The use of corrosion inhibitors is the more appropriate method, and its maintenance cost is high. One alternative way to prevent the corrosion of high-performance concrete (HPC) by improving impermeability, resistance to chloride ion diffusion [15], and abrasion resistance can be achieved through the partial replacement of cement with industrial byproducts (supplementary cementing materials (SCMs)) such as fly-ash (FA) [16], ground granulated blast furnace slag (GGBFS) [17], silica fume, rice husk ash [18], and micro silica. 
TABLE 1: Chemical composition and physical properties of OPC, GGBFS, and FA.

\begin{tabular}{|c|c|c|c|c|c|c|c|c|c|}
\hline \multirow{3}{*}{ Types } & & \multicolumn{8}{|c|}{ Items } \\
\hline & \multicolumn{7}{|c|}{ Chemical composition (mass \%) } & \multicolumn{2}{|c|}{ Physical properties } \\
\hline & $\mathrm{SiO}_{2}$ & $\mathrm{Al}_{2} \mathrm{O}_{3}$ & $\mathrm{Fe}_{2} \mathrm{O}_{3}$ & $\mathrm{CaO}$ & $\mathrm{MgO}$ & $\mathrm{SO}_{3}$ & Lg.loss & $\begin{array}{c}\text { Specific gravity } \\
\left(\mathrm{g} / \mathrm{cm}^{3}\right)\end{array}$ & $\begin{array}{l}\text { Blaine } \\
\left(\mathrm{cm}^{2} / \mathrm{g}\right)\end{array}$ \\
\hline OPC & 21.96 & 5.27 & 3.44 & 63.41 & 2.13 & 1.96 & 0.79 & 3.16 & 3,214 \\
\hline GGBFS & 32.74 & 13.23 & 0.41 & 44.14 & 5.62 & 1.84 & 0.2 & 2.89 & 4,340 \\
\hline FA & 55.66 & 27.76 & 7.04 & 2.70 & 1.14 & 0.49 & 4.3 & 2.19 & 3,621 \\
\hline
\end{tabular}

In South Korea, the annual production amount of FA was 8.5 million tons in coal-fired power plants and GGBFS (produced by POSCO and Hyundai Steel) was about 12 million tons/year as of 2011 [19]. Compared to the Ordinary Portland Cement (OPC), it is very low regarding emission of environmental load. Hence, it has been mostly used as a component of low carbon emission concrete [20]. Replacing OPC with GGBFS and FA in high-performance concrete (HPC) and self-compacting concretes (SCC) are becoming increasingly common in civil engineering structures [21]. Utilizing FA and GGBFS for the production of HPC and SCC not only reduces the total material cost of the construction industry but also results in considerable benefits to the environment [22]. In addition, the use of FA and GGBFS in the SCC has a unique and distinctive effect on the properties of the HPC. Further, the replacement of OPC with GGBFS and FA in SCC had a lower resistance to carbonation than the pure OPC-blended SCC. This effect appeared to be more pronounced with an increase in the replacement level of FA and GGBFS [23]. Moreover, utilizing FA and GGBFS in SCC is more effective in resisting the chloride ion and sulphate ion migration and reducing the capillary pores. The chloride ion diffusion coefficient of the SCC mixtures with FA and GGBFS was lower than the control SCC [24-26]. In addition, GGBFS and FA have pozzolanic activity which is attributed to the presence of $\mathrm{SiO}_{2}$ and $\mathrm{Al}_{2} \mathrm{O}_{3}$. It reacts with calcium hydroxide during cement hydration to form additional calcium silicate hydrate $(\mathrm{CSH})$ and calcium aluminate hydrate $(\mathrm{CAH})$, which are effective in forming denser matrix leading to higher strength and better durability [27-29]. Furthermore, according to Yuan et al., GGBFS and FA increase chloride binding due to the high content of aluminate hydrates and hence chloride migration was reduced in HPC [30]. The research field on the evaluation of chloride diffusion in concrete is growing with consideration for diffusion, permeation [31], and binding capacity of chloride ions $[32,33]$. Recently, numerical techniques covering chloride diffusion in partially saturated condition [34], chloride behavior in concrete with early-age cracking [35], and micro structures formation modeling in high-performance concrete $[36,37]$ were proposed based on behavior in early-age concrete considering hydration and micro pore structure.

In this work, 4000 specimens for 15 mix proportions with various water-binder $(w / b)$ material ratios $(0.37,0.42$, and 0.47 ) and various replacement percentages of GGBFS and FA $(0 \%, 30$, and $50 \%)$ are prepared and cured in tap water. As a part of the work, half of the samples analysis is going on at KCL (Korea Conformity Laboratory, Korea) by exposing to tidal, atmosphere, and submerged conditions to know long term durability for 100 years. The apparent diffusion coefficient and porosity will be measured by using RCPT (Q) and MIP to know long term durability for 100 years. The samples will be measured at different intervals of time period: $0.6,1,2,3,4,5,7,10,20,40,80$, and 100 years. The compressive strength, electrical charges, and chloride diffusion coefficient in nonsteady state and steady state conditions were measured. In order to evaluate the microstructure characteristics, porosity through MIP was also measured. From this work, timedependent diffusion coefficients in HPC and key parameters for durability design are proposed. The results showed that partial replacement of OPC with GGBFS and FA contributed considerable improvement to various properties of HPC.

\section{Experimental Program}

2.1. Materials Used. Ordinary Portland Cement (OPC) of Type 1 with specific gravity 3.16 was used. Chemical compositions of OPC, FA, and GGBFS are given in Table 1. River sand was used as fine aggregate, passing through $2.36 \mathrm{~mm}$ sieve, falling under zone and with specific gravity of 2.60. Coarse aggregates used were crushed angular aggregates of normal size $19 \mathrm{~mm}$ with specific gravity 2.62 .

2.2. Concrete Mix Proportion. In this study, a total of 15 HPC mixtures were prepared; OPC partial replacement with GGBFS and FA in three replacement ratios like 0,30 , and 50\% were considered for HPC mixtures. Three water-to-binder material $(w / b)$ ratios $(0.37,0.42$, and 0.47$)$ were used. The details of the mixing proportions of the HPC are shown in Table 2.

\subsection{Test Program}

2.3.1. Compressive Strength. The compressive strength of the various concrete mixers was calculated according to ASTM C39/C39M [39] using cylindrical specimens of $100 \mathrm{~mm}$ in diameter and $200 \mathrm{~mm}$ in height, cast with different percentage of FA and GGBFS (HPC). After curing in room condition for 24 hours, the specimens were demoulded and immersed in water for curing at $25^{\circ} \mathrm{C}$. The compressive strength was measured after 28 and 49 days of curing, the concrete cylinders were tested in the compression-testing machine, with $100 \mathrm{~T}$ capacities at the rate of loading $140 \mathrm{kN} / \mathrm{min}$. The ultimate load at which the cube failed was taken. 
TABLE 2: Mixing proportion of HPC.

\begin{tabular}{|c|c|c|c|c|c|c|c|}
\hline System & $\begin{array}{c}w / b \text { ratio } \\
(\%)\end{array}$ & $\begin{array}{c}\text { Water } \\
\left(\mathrm{kg} / \mathrm{m}^{3}\right)\end{array}$ & $\begin{array}{l}\text { Cement } \\
\left(\mathrm{kg} / \mathrm{m}^{3}\right)\end{array}$ & $\begin{array}{l}\text { Fly-ash } \\
\left(\mathrm{kg} / \mathrm{m}^{3}\right)\end{array}$ & $\begin{array}{l}\text { GGBFS } \\
\left(\mathrm{kg} / \mathrm{m}^{3}\right)\end{array}$ & $\begin{array}{c}\text { Coarse aggregates } \\
\left(\mathrm{kg} / \mathrm{m}^{3}\right)\end{array}$ & $\begin{array}{c}\text { Fine aggregates } \\
\left(\mathrm{kg} / \mathrm{m}^{3}\right)\end{array}$ \\
\hline \multirow{3}{*}{ O100 } & 0.37 & 168 & 454 & 0.0 & 0.0 & 952 & 767 \\
\hline & 0.42 & 168 & 400 & 0.0 & 0.0 & 976 & 787 \\
\hline & 0.47 & 168 & 357 & 0.0 & 0.0 & 960 & 838 \\
\hline \multirow{3}{*}{ O70S30 } & 0.37 & 168 & 318 & 0.0 & 136 & 946 & 762 \\
\hline & 0.42 & 168 & 280 & 0.0 & 120 & 972 & 783 \\
\hline & 0.47 & 168 & 250 & 0.0 & 107 & 956 & 835 \\
\hline \multirow{3}{*}{ O50S50 } & 0.37 & 168 & 227 & 0.0 & 227 & 943 & 760 \\
\hline & 0.42 & 168 & 200 & 0.0 & 200 & 969 & 780 \\
\hline & 0.47 & 168 & 179 & 0.0 & 179 & 853 & 832 \\
\hline \multirow{3}{*}{ O70F30 } & 0.37 & 168 & 318 & 136 & 0.0 & 952 & 745 \\
\hline & 0.42 & 168 & 280 & 120 & 0.0 & 953 & 768 \\
\hline & 0.47 & 168 & 250 & 107 & 0.0 & 939 & 820 \\
\hline \multirow{3}{*}{ O50F50 } & 0.37 & 168 & 227 & 227 & 0.0 & 950 & 662 \\
\hline & 0.42 & 168 & 200 & 200 & 0.0 & 982 & 685 \\
\hline & 0.47 & 168 & 179 & 179 & 0.0 & 1008 & 703 \\
\hline
\end{tabular}

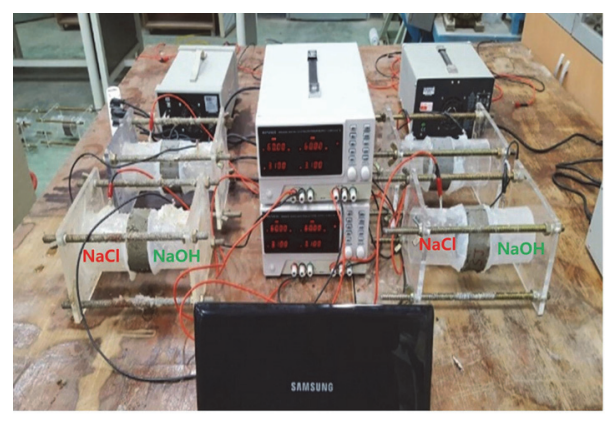

FIGURE 1: The photograph image of RCPT experiment setup.

2.3.2. Rapid Chloride Ion Penetration Test (RCPT). The rapid chloride ion permeability test (RCPT) was conducted in accordance with ASTM C1202-10 [38] using a concrete disc of size $100 \mathrm{~mm}$ diameter and $50 \mathrm{~mm}$ thickness. After 28 days of curing, the concrete specimens were subjected to RCPT test by impressing a voltage of $60 \mathrm{~V}$ between two containers filled with $3 \% \mathrm{NaCl}$ solution and $0.3 \mathrm{~N} \mathrm{NaOH}$ solutions, as shown in Figure 1. Electrical current was measured every 30 minutes for up to 6 hours. The amount of electrical current passing through the specimen was measured and the total charge passed (in coulombs) was used as an indicator of the resistance of the concrete to chloride ion penetration. The total charge passed through the concrete specimens was calculated using the following formula [38]:

$$
Q=900\left(I_{0}+2 I_{30}+2 I_{60}+\cdots+2 I_{300}+2 I_{330}+I_{360}\right),
$$

where $Q$ is charge passed (coulombs), $I_{0}$ is current (amperes) immediately after voltage is applied, and $I t$ is current (amperes) at $t$ min after the voltage is applied.
2.3.3. Chloride Diffusion. Chloride diffusion coefficient method is the extension of the RCPT test. The chloride diffusion coefficient values were calculated by the two conditions such as steady state condition based on the results from ASTM $[38,40]$ and nonsteady state condition from Tang's method [40, 41]. In RCPT test, the time duration is 6 hours where it is under nonsteady state condition. The diffusion cell and experimental set up is provided in ASTMC 1202 [38] and the calculation of the diffusion coefficient is performed by an electrical method proposed by previous researches [40,41]. Silver nitrate solution $\left(0.1 \mathrm{~N}, \mathrm{AgNO}_{3}\right)$ is used as an indicator $[42,43]$. In this test, chloride diffusion coefficient in nonsteady state conditions and steady state condition (effective diffusion) was calculated using (2a) and (2b) and (3), respectively.

$$
\begin{aligned}
D_{\text {cpd }} & =\frac{R T L}{z F U} \cdot \frac{X_{d}-\alpha \sqrt{X_{d}}}{t}, \\
\alpha & =2 \sqrt{\frac{R T L}{z F U}} \cdot \operatorname{erf}^{-1}\left[1-\frac{2 C_{d}}{C_{0}}\right], \\
D_{\text {eff }} & =0.0103\left(Q_{0}\right)^{0.84} E-8,
\end{aligned}
$$

where $D_{\text {cpd }}$ is diffusion coefficient in nonsteady state and steady state condition from RCPT $\left(\mathrm{m}^{2} / \mathrm{s}\right), R$ is universal gas constant $(8.314 \mathrm{~J} / \mathrm{mol} \mathrm{K}), T$ is absolute temperature $(\mathrm{K}), L$ is thickness of specimen $(\mathrm{m}), z$ is ionic valence $(=1.0), F$ is Faraday constant $(=96,500 \mathrm{~J} / \mathrm{V} \mathrm{mol}), U$ is applied potential $(\mathrm{V}), t$ is test duration time (s), $C_{d}$ is the chloride concentration at which the color changes when using a colorimetric method to measure $X_{d}$ based on the reference $[40,42], C_{0}$ is chloride concentration in the upstream solution $(\mathrm{mol} / \mathrm{l}), \alpha$ is an experimental constant, and $\operatorname{erf}^{-1}$ is the inverse function of the error function. According to the previous research [40], $\operatorname{erf}^{-1}\left(1-\left(2 C_{d} / C_{0}\right)\right)$ is calculated as 0.764 and $z F U / R T L$ 


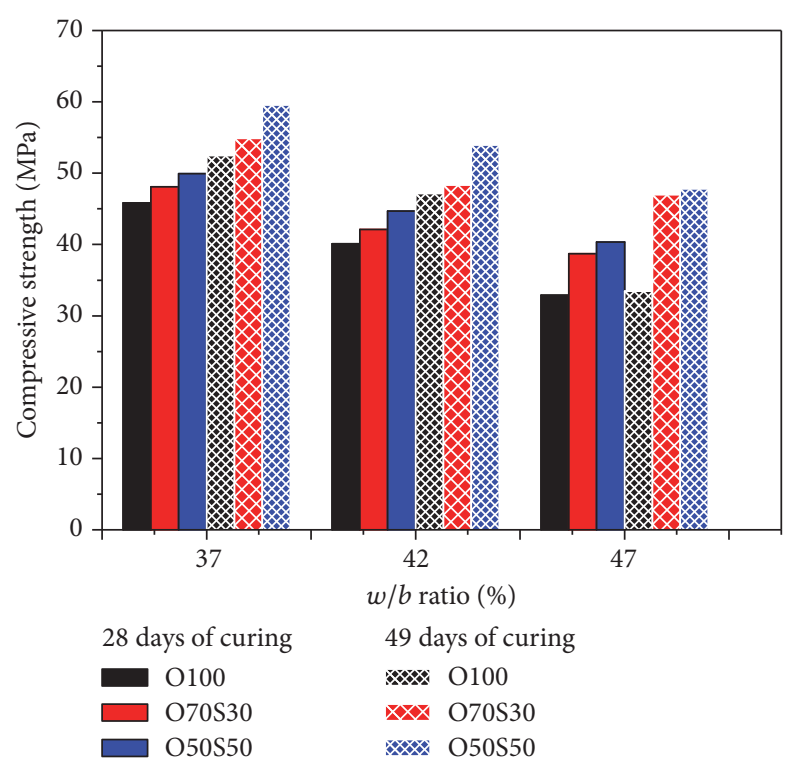

(a)

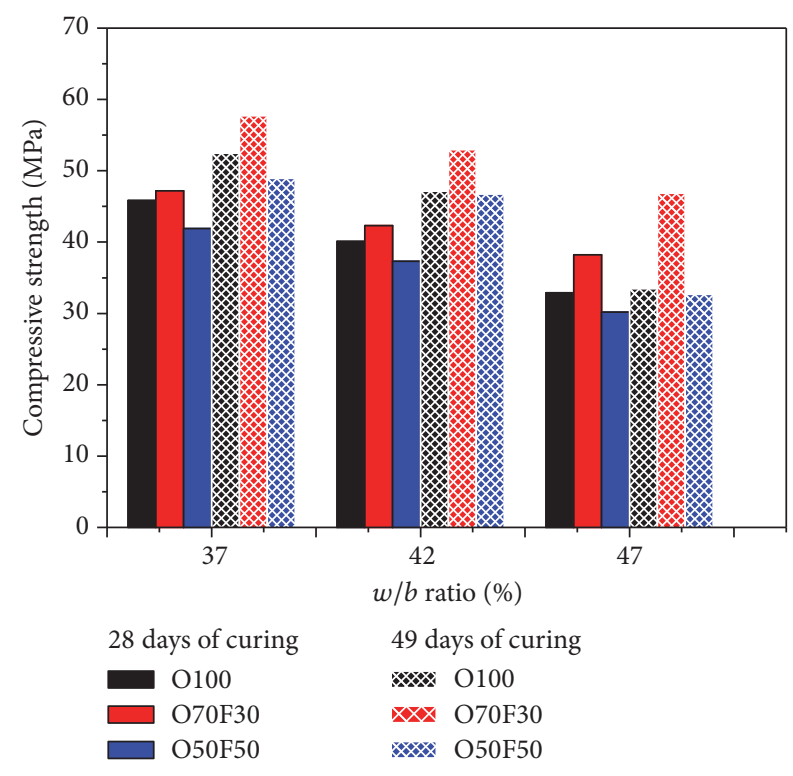

(b)

FIgURE 2: Compressive strength of HPC with (a) GGBFS and (b) FA at 28- and 49-day curing period.

is $23,600\left(\mathrm{~m}^{-1}\right)$ in this study. $D_{\text {eff }}$ means effective diffusion coefficient in RCPT test.

2.4. Porosity Measurement. The porosity of concrete specimens at the age of 28 days was also investigated through the mercury intrusion porosimetry (MIP) test (ASTM D 4404) [44]. MIP (Micromeritics, Autopore IV 9520, USA) has been one of the most widely used methods to analyze the pore structure of HPC samples. When preparing samples for MIP test, aggregates were avoided from sampling and about $1 \mathrm{~cm}^{3}$ volumes $(2.4 \sim 3.6 \mathrm{~g})$ were placed in the quanta chrome porosity analyzer and a sample was used for each measurement. The intruded volume could be read to an accuracy of $\pm 0.001 \mathrm{~cm}^{3}$.

\section{Results and Discussion}

3.1. Compressive Strength. The compressive strength of HPC with different percentages of GGBFS and FA at the age of 28 and 49 days as per KS F 2405 is shown in Figure 2. It was observed from the results that, at the age of 28 days and above, there has been an increase in compressive strength up to $30-50 \%$ replacement level of GGBFS in 0.37 of $w / b$ ratio. The increase in 28 days strength of HPC mixes is due to the improvement in the effectiveness of the mineral admixture. The pozzolanic action of GGBFS reacts with OPC, which yields early strength at lower $w / b$ ratios. The similar results are also reported by Tripathi et al. [45]. They reported that, at the age of 28 days at lower $w / b$ ratio, the compressive strength of concrete with ISF slag was higher than control mix concrete even at $60 \%$ replacement level. Moreover, the compressive strength values of GGBFS concrete at 49-day curing period was higher when compared to all the other HPC mixes, where the mix proportions of OPC: GGBFS were $70: 30$ and $50: 50$ at $w / b$ of 0.37 .
On the other hand, another system of compressive strength of HPC with different percentage of FA at the age of 28 and 49 days has increased up to $30 \%$ replacement level of FA in 0.37 of $w / b$ ratio and decreasing thereafter $(50 \%$ replacement of FA). An increase in the compressive strength of HPC by up to $30 \%$ in replacement FA when compared with the control mix may be due to the pozzolanic action and packing effect of FA particles. FA contains more of silica and alumina; it reacts with calcium hydroxide to form C-A$\mathrm{S}-\mathrm{H}$ and C-S-H, which contributes to the higher strength of $30 \%$ of FA in HPC. Further, by replacing FA by up to $50 \%$, strength has been reduced due to the weak bonding between cement paste and fly-ash particles and insufficient alkali from the reduced OPC amount.

In addition, the compressive strength was slightly reduced by increasing $w / b(0.42$ and 0.47$)$ ratio in HPC mix with GGBFS and FA replacement level. The increasing $w / b$ ratio dilutes the cement paste and creates more water-filled pore space between the grains, that is, less nuclei for the hydrates in each volume unit. Hydrates have to grow larger and larger to cover the spatial gap (the water) between them and to interact and to develop strength-either physically (interlocked growth) or chemically (e.g., van-der-Waals attraction).

3.2. Rapid Chloride Ion Penetration Test (RCPT). Rapid chloride permeability test was conducted to investigate the performance of HPC against chloride ingress. The total charge passed through the concrete matrix is lower and it means the resistance to chloride penetration is higher. Table 3 shows the classification of concrete for chloride ion penetrability based on total charge passed ASTM C1202 [38].

Figure 3 shows the RCPT test results at the end of 28 days for the HPC with various percentages of GGBFS and FA. Figure 3 illustrates that the cement replacement with 
TABLE 3: Chloride ion penetrability based on charge passed [38].

\begin{tabular}{lc}
\hline Charge passed (c) & $\begin{array}{c}\text { Chloride ion } \\
\text { permeability }\end{array}$ \\
\hline$>4,000$ & High \\
$2,000-4,000$ & Moderate \\
$1,000-2,000$ & Low \\
$100-1,000$ & Very low \\
$<100$ & Negligible \\
\hline
\end{tabular}

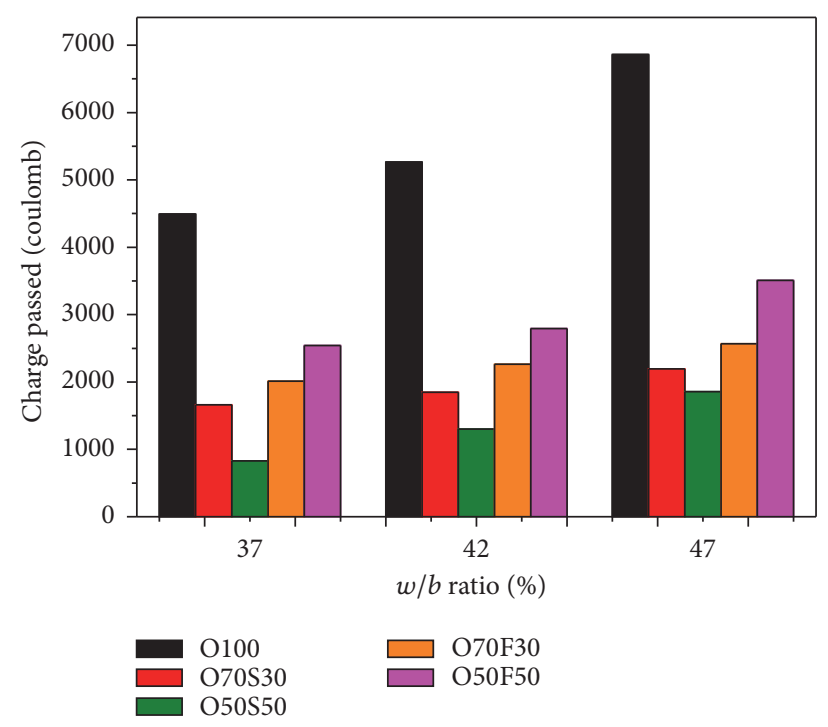

FIgURE 3: RCPT results of HPC with GGBFS and FA.

GGBFS in HPC $(0.37 \%$ of $w / b)$ had lesser coulomb values when compared to control mix. For example, the $30 \%$ and $50 \%$ replacement level of GGGFS in $0.37 \% w / b$ ratio of HPC charge passed coulomb values are 1659.6 and 829.8 coulomb. This may be due to the reaction of pozzolanic materials like GGBFS reacting with $\mathrm{Ca}(\mathrm{OH})_{2}$ to form C-S-H gel. The C-S$\mathrm{H}$ gel considerably reduces pores between fine aggregate and coarse aggregate, so charge passed values may be significantly reduced through the GGBFS replaced HPC. At the same time with increasing $w / b(0.42$ and $0.47 \%)$ ratio, the charge passed coulomb values slightly increase. It may be due to the more dilute cement paste which creates more water-filled pore space between the grains.

Figure 3 shows the charge passed results in cement replacement with FA in HPC. From the figure, it is observed that $30 \%$ of FA in HPC has lower values when compared to the control mix. For example, the charge passed result in the system with $30 \%$ replacement and 0.37 of $w / b$ ratio is 2012.4 coulomb. Further, the replacement of FA up to $50 \%$ charge passed coulomb values (2541 coulomb) significantly increases when compared to $30 \%$ of FA in HPC. This result indicates that the presence of 50\% GGBFS and 30\% FA in $\mathrm{HPC}$ can be more efficient in preventing chloride ion migration.

\subsection{Chloride Diffusion}

3.3.1. Nonsteady State Condition. The chloride diffusion coefficient at nonsteady state condition (6 hours during test) in HPC containing various replacement ratios $(0 \%, 30 \%$, and $50 \%)$ and $w / b$ ratios are shown in Figure 4 . In the condition of 28-day curing. In Figure 4(a), the results in HPC with replacement level of 50\% GGBFS at various $w / b$ ratios of $0.37 \%, 0.42 \%$, and 0.47 at 28 days are $6.4640 \times$ $10^{-12}, 6.5330 \times 10^{-12}$, and $7.1102 \times 10^{-12}$, respectively. The incorporation of GGBFS into the HPC resulted in a lower chloride ion diffusion coefficient in nonsteady state condition when compared to control mix.

Figure 4(b) shows the results in the HPC with FA from $0 \%$ to $30 \%$, which shows that the diffusion coefficients in the HPC drastically decrease. Regarding the replacement level of FA up to $50 \%$, the chloride diffusion coefficient in the FAblended HPC begins to increase with increasing $w / b$ ratio of HPC with FA and it has also significant increases when compared to lower $w / b$ ratio of HPC. Zhao et al. [21] also reported that, at the age of 28 days at lower $w / b$ ratio, the chloride diffusion coefficient of concrete with FA was lower than control mix even at 30\% replacement level. Further, they also reported that increasing the replacement level FA up to $50 \%$ of FA the chloride ion diffusion coefficient also increased.

3.3.2. Steady State Condition (Effective Diffusion). The chloride diffusion coefficient at steady state condition in HPC with the replacement of GGBFS and FA in different $w / b$ ratio systems is shown in Figure 5. The chloride diffusion coefficient also decreases with the replacement level of $30 \%$ and 50\% GGBFS in HPC when compared to the control mix. For example, control mix and 50\% of GGBFS in HPC $(0.37$ $w / b)$ are $1.2053 \times 10^{-11} \mathrm{~m}^{2} / \mathrm{sec}$ and $0.2916 \times 10^{-11} \mathrm{~m}^{2} / \mathrm{sec}$, respectively. The reduction of chloride diffusion is $75.8 \%$ when compared with the control mix. This diffusion coefficient data confirms the better performance of $50 \%$ GGBFS in HPC.

On the other hand it was observed that $30 \%$ of FA in HPC has lower chloride diffusion coefficient when compared to the control mix. For example, control mix and 30\% of FA in HPC $(0.37 w / b)$ are $1.2053 \times 10^{-11} \mathrm{~m}^{2} / \mathrm{sec}$ and $0.6137 \times 10^{-11} \mathrm{~m}^{2} / \mathrm{sec}$, respectively. The reduction of chloride diffusion is $49.1 \%$ when compared to control mix. At the same time, the chloride diffusion coefficients of HPC with the replacement of GGBFS and FA (lower $w / b$ ratio) at steady state condition significantly decrease when compared to nonsteady state condition. It may be due to absorption of chloride ion and formation of bound chloride (Friedel salt) [46]. Moreover, the HPC with GGBFS exhibits lower chloride diffusion coefficient values than HPC with FA. It may depend on the aluminate content, where aluminate in GGBFS and FA forms AFm phases which react with chloride and also produces the calcium chloroaluminate hydrate and Friedel's salt [47]. Moreover, at a given replacement level, the HPC samples with GGBFS had a lower chloride ion diffusion coefficient than those with FA. 


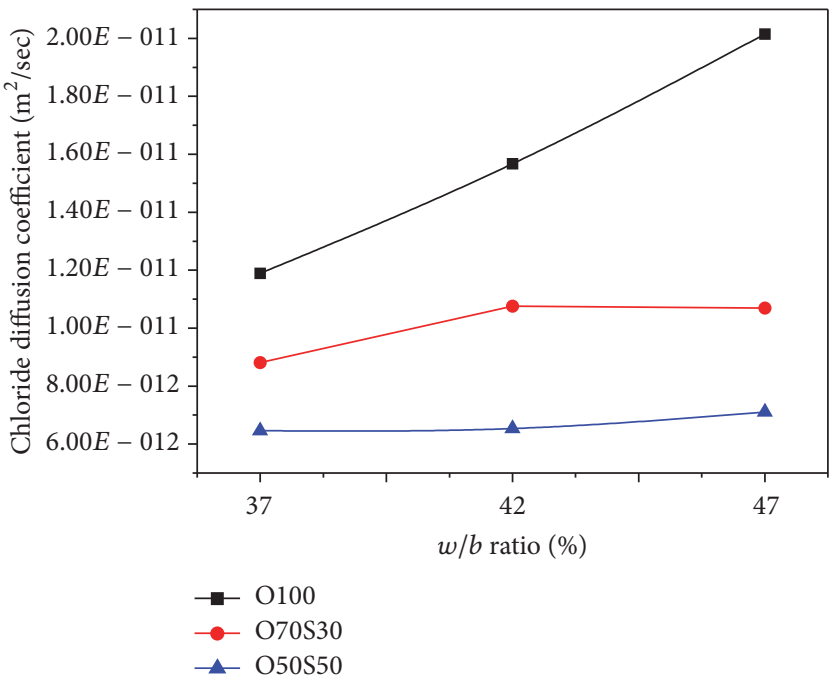

(a)

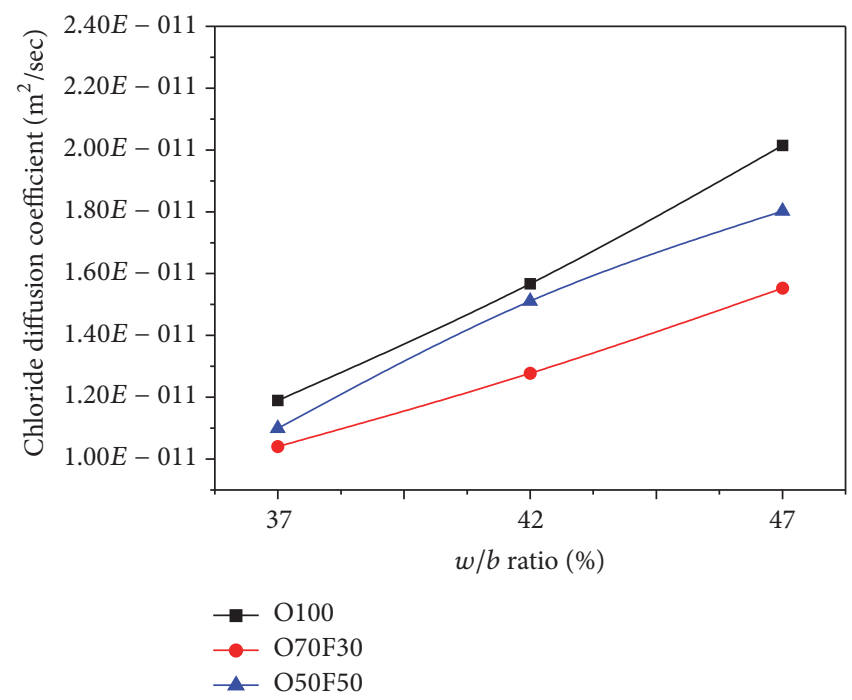

(b)

FIGURE 4: Chloride diffusion coefficient of HPC with (a) GGBFS and (b) FA at nonsteady state condition.

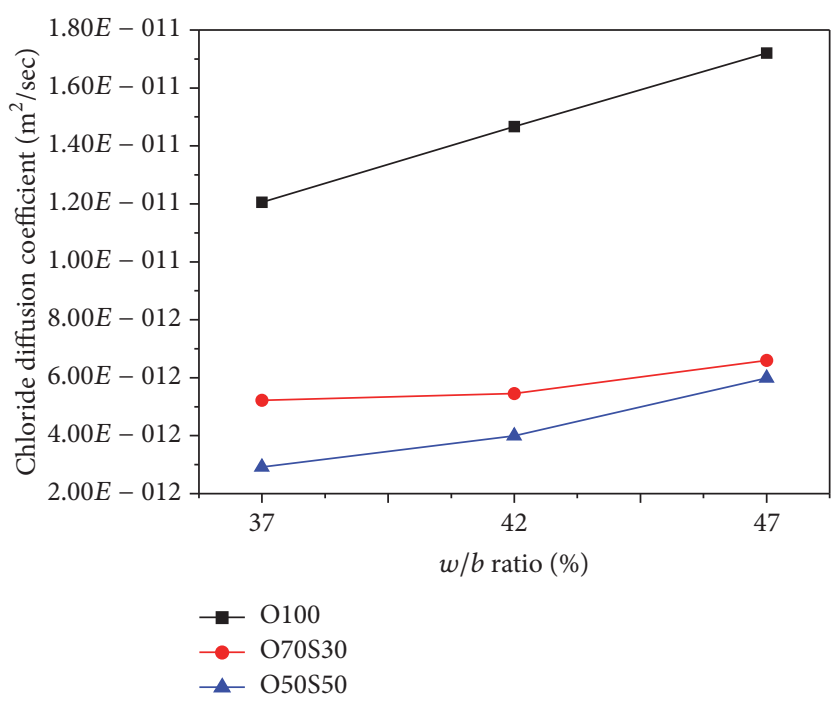

(a)

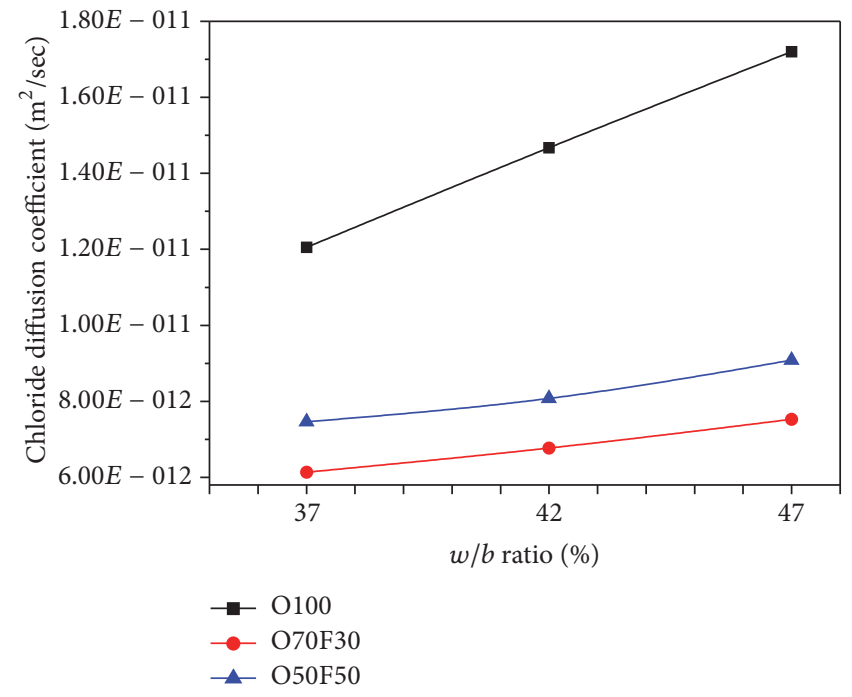

(b)

FIGURE 5: Chloride diffusion coefficient of HPC with (a) GGBFS and (b) FA at steady state condition.

3.4. Porosity Measurement. Figure 6 shows the total porosity measurement for GGBFS (a) and FA (b) replaced HPC by MIP test at 28 days of water curing. As shown in Figure 6(a), an increase in the percentage of GGBFS with HPC reduces the average pore size diameter by 8.53 and $7.33 \%$ for 30 and $50 \%$ GGBFS replacement, respectively. Further increase in the $w / b$ ratio $(0.42$ and 0.47$)$ in $30 \%$ and $50 \%$ GGBFS on porosity at 28 days of curing significantly increases. For example, at various $0.37,0.42$, and $0.47 \% w / b$ ratios of $50 \%$ GGBFS replacement of HPC, the porosity results are 7.33, 8.95, and $10.38 \%$. As shown in Figure 6(b), the $30 \%$ of FA with HPC, porosity is $7.29 \%$ at $0.37 \% w / b$ ratio. Increasing the percentage of FA and $w / b$ ratio, the porosity slightly increases. At a given replacement level, the HPC samples with GGBFS had a lower pore diameter than those with FA.
3.5. Correlation between Test Results. Figures 7-9 present the relationship between compressive strength (CS), chloride diffusion coefficient (CDC), and porosity $(P)$ against charge passed coulombs (CPC). Table 4 shows the numerical representation to determine the correlation between these properties of HPC with GGBFS and FA.

Figures 7(a) and 7(b) show the increase in CS attributed to the decrease of the CPC for all mixes of HPC. However, CS decreases with an increase in $w / b$ ratio for all mixes of HPC. Also, it meagerly increases by replacing GGBFS and FA of HPC (Figures 7(a) and 7(b)). In addition, a good correlation is observed between CPC and CS. The same CS value is obtained in all mixes of HPC that showed different values of CPC. For example, at CS of $40 \mathrm{MPa}$ in all mixes of HPC, the CPC values are around 5266.8 coulombs for control mix and 


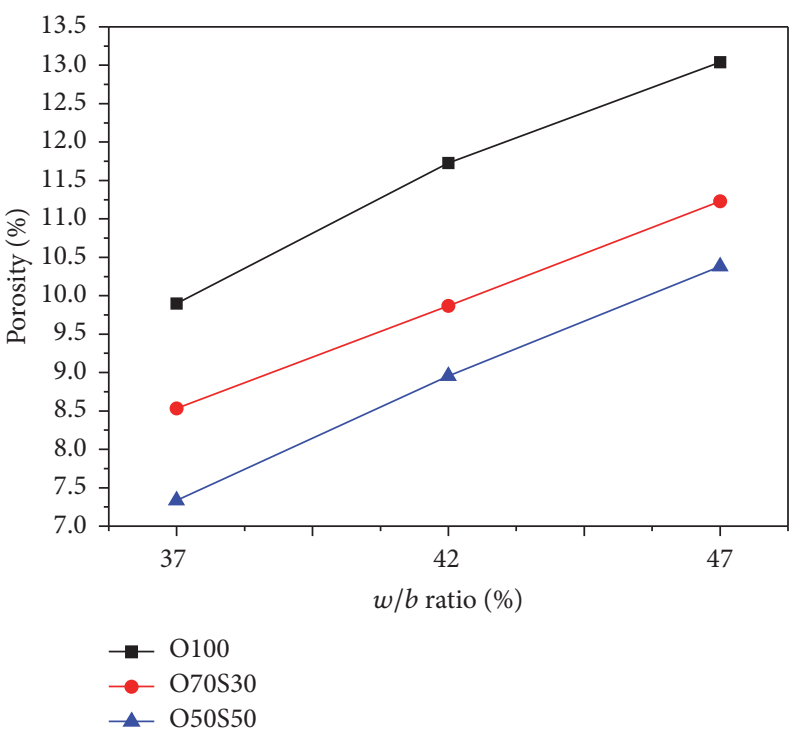

(a)

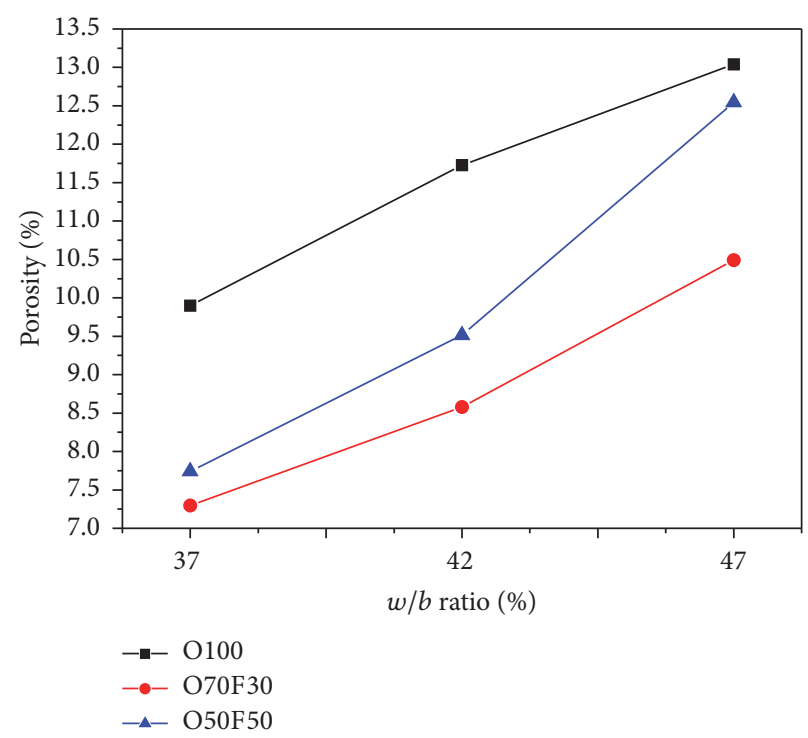

(b)

FIgURE 6: Porosity of HPC with (a) GGBFS and (b) FA.

TABLE 4: Result of compressive strength, charge passed coulomb, chloride diffusion coefficient, and porosity of concrete.

\begin{tabular}{|c|c|c|c|c|c|c|}
\hline System & $\begin{array}{c}w / b \text { ratio } \\
(\%)\end{array}$ & $\begin{array}{l}\text { Cement } \\
(\mathrm{kg})\end{array}$ & $\begin{array}{c}{ }^{*} \mathrm{CPC} \\
\text { (coulomb) }\end{array}$ & $\begin{array}{c}{ }^{*} \mathrm{CS} \\
(\mathrm{MPa})\end{array}$ & $\begin{array}{c}{ }^{*} \mathrm{CDC} \\
\left(\mathrm{m}^{2} / \mathrm{sec}\right) \\
\times 10^{-11}\end{array}$ & $\begin{array}{c}\text { Porosity } \\
\text { (\%) }\end{array}$ \\
\hline \multirow{3}{*}{$\mathrm{O} 100$} & 0.37 & 104.4 & 4494.6 & 45.85 & 1.2053 & 9.89 \\
\hline & 0.42 & 92.0 & 5266.8 & 40.09 & 1.4670 & 11.72 \\
\hline & 0.47 & 82.1 & 6863.4 & 32.9 & 1.7200 & 13.03 \\
\hline \multirow{3}{*}{ O70S30 } & 0.37 & 73.1 & 1659.6 & 48.09 & 0.5219 & 8.53 \\
\hline & 0.42 & 64.4 & 1847.8 & 42.02 & 0.5452 & 9.86 \\
\hline & 0.47 & 57.5 & 2194.2 & 38.69 & 0.6599 & 11.22 \\
\hline \multirow{3}{*}{ O50S50 } & 0.37 & 52.2 & 829.8 & 49.94 & 0.2916 & 7.33 \\
\hline & 0.42 & 46.0 & 1300 & 44.67 & 0.3993 & 8.95 \\
\hline & 0.47 & 41.2 & 1854.8 & 40.36 & 0.5989 & 10.38 \\
\hline \multirow{3}{*}{ O70F30 } & 0.37 & 73.1 & 2012.4 & 47.17 & 0.6137 & 7.29 \\
\hline & 0.42 & 64.4 & 2262.6 & 42.33 & 0.6772 & 8.57 \\
\hline & 0.47 & 57.5 & 2566.8 & 38.2 & 0.7529 & 10.49 \\
\hline \multirow{3}{*}{ O50F50 } & 0.37 & 52.2 & 2541.6 & 41.92 & 0.7466 & 7.74 \\
\hline & 0.42 & 46.0 & 2791.8 & 37.33 & 0.8079 & 9.51 \\
\hline & 0.47 & 40.9 & 3509.4 & 30.2 & 0.9083 & 12.54 \\
\hline
\end{tabular}

${ }^{*} \mathrm{CPC}$ : charge passed coulomb; ${ }^{*} \mathrm{CS}$ : compressive strength; ${ }^{*} \mathrm{CDC}$ : chloride diffusion coefficient.

1847 coulombs and 1854 coulombs for 30 and 50\% GGBFS of HPC, respectively. 2262 coulombs and 2541 coulombs are for 30 and 50\% FA of HPC. This is due to the microstructure of concrete and secondary formation of calcium silicate hydrate by using various percentages of GGBFS and FA of HPC in different $w / b$ ratio. Similar correlations between CPC and CDC are shown in Figures 8(a) and 8(b). Moreover, Figures 9(a) and 9(b) illustrated a good correlation between CPC and porosity of HPC. However, the same porosity values are obtained in all mixes of HPC that showed different values of
CPC. For example, with $10 \%$ of porosity in all mixes of HPC, the CPC values obtained around 4494.6 coulombs for control mix and 1847 coulombs and 1854 coulombs for 30 and 50\% GGBFS of HPC. 2566 coulombs and 2791 coulombs are for 30 and 50\% FA of HPC. This may be due to the difference in the microstructure of concrete prepared using different type of pozzolanic materials [48] (GGBFS, FA) and mix design. It causes the reduction of the pores, resulting in a dense microstructure and hence reduces the charge passed coulomb on concrete $[49,50]$. 


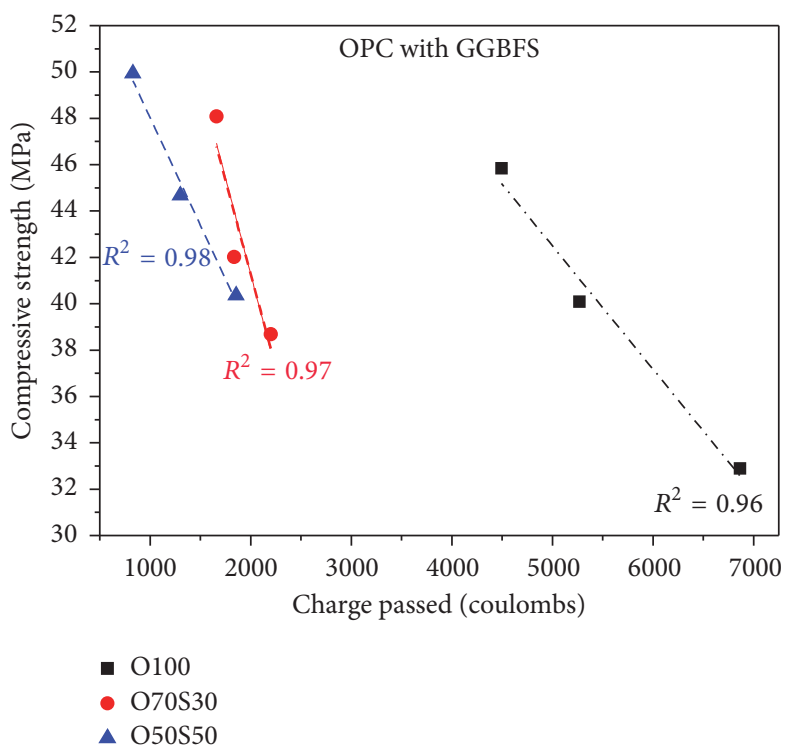

(a)

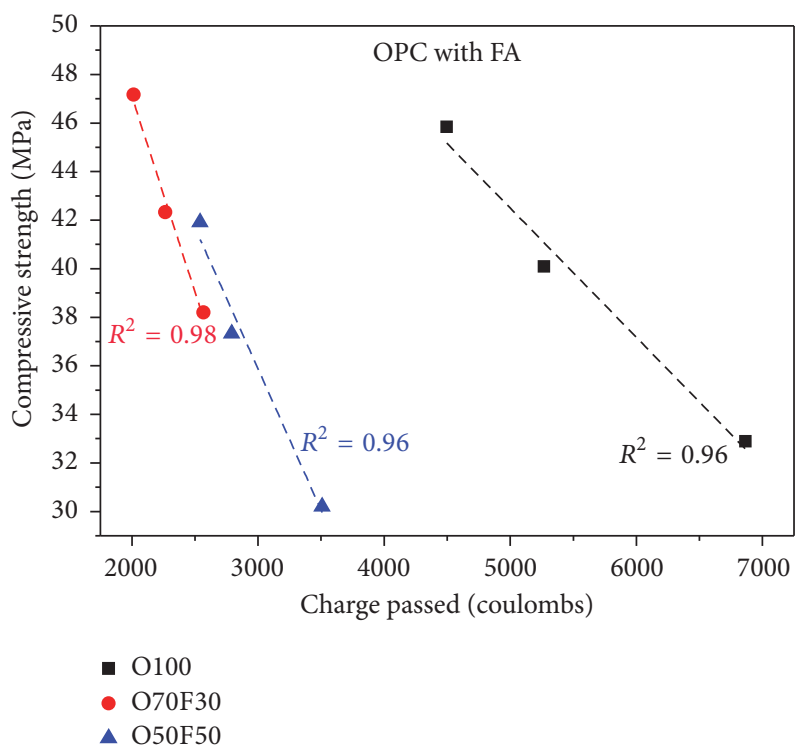

(b)

FIGURE 7: Correlation graph between charge passed coulomb versus compressive strength: (a) GGBFS in HPC and (b) FA in HPC.

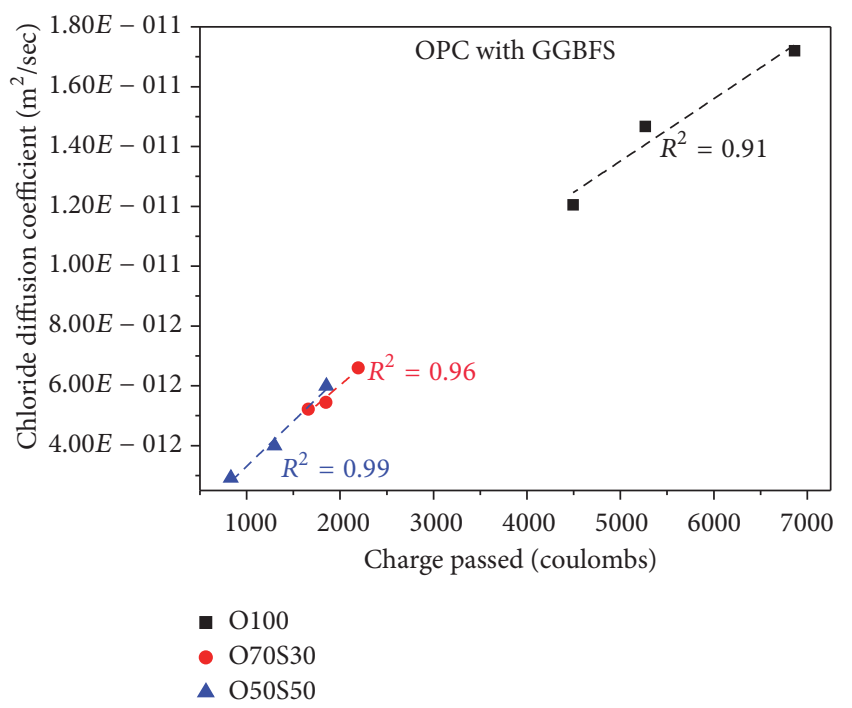

(a)

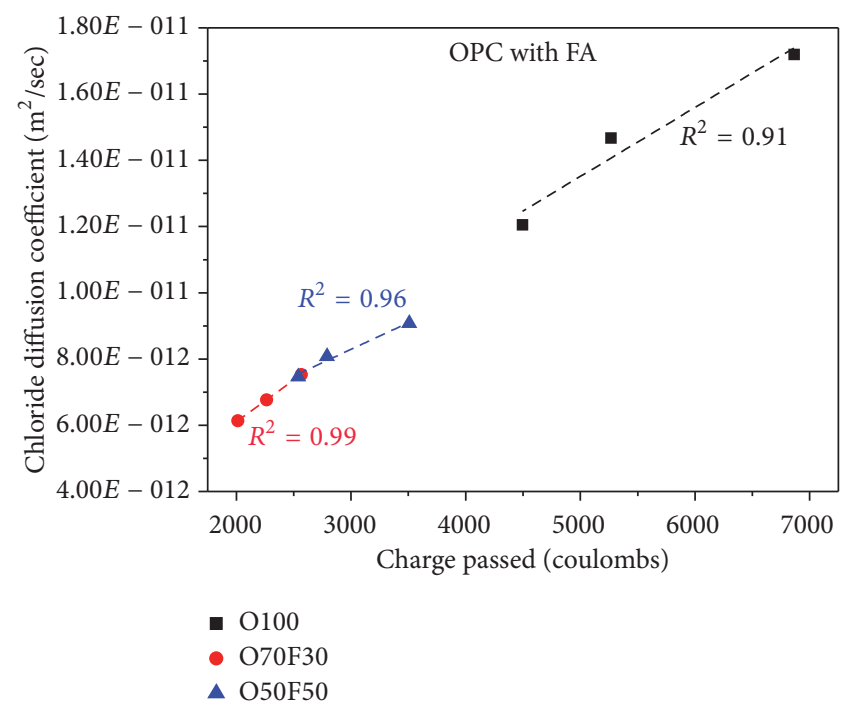

(b)

FIGURE 8: Correlation graph between charge passed coulomb versus chloride diffusion coefficient: (a) GGBFS in HPC and (b) FA in HPC.

The correlation equation can be expressed by the following single formula as reported elsewhere [51]:

$$
\mathrm{DI}=\frac{a}{\left(f_{\mathrm{CPC}}\right)^{b}},
$$

where DI is the durability index and " $a$ " and " $b$ " are the experimental constants. The $f_{\mathrm{CPC}}$ charge passed coulomb. The constants " $a$ " and " $b$ " were obtained through the regression analysis of the data in Table 4 . The best-fit values of constants $a$ and $b$ and the coefficient of determination $\left(R^{2}\right)$ are summarized in Table 5 .

$R^{2}$ over 0.85 indicates an excellent correlation between the fitted parameters [52]. Therefore, the data in Table 5 indicate a valid agreement between the CPC and CS of the replacement with GGBFS and FA of HPC. Furthermore, the data in Table 5 also indicates that an excellent fit correlation between CPC is plotted against CS and CDC of all types of mix concrete. However, in the case of control mix of concrete, the degree of the bit between the CPC and porosity of concrete is on the lower side $\left(R^{2}<0.83\right)$ but reasonably correlated.

\section{Conclusion}

The conclusions drawn from this work are as follows.

(1) The $0.37 w / b$ ratio of HPC containing 50\% GGBFS and 30\% FA yields the highest compressive strength values at 28 and 49 days of curing. 


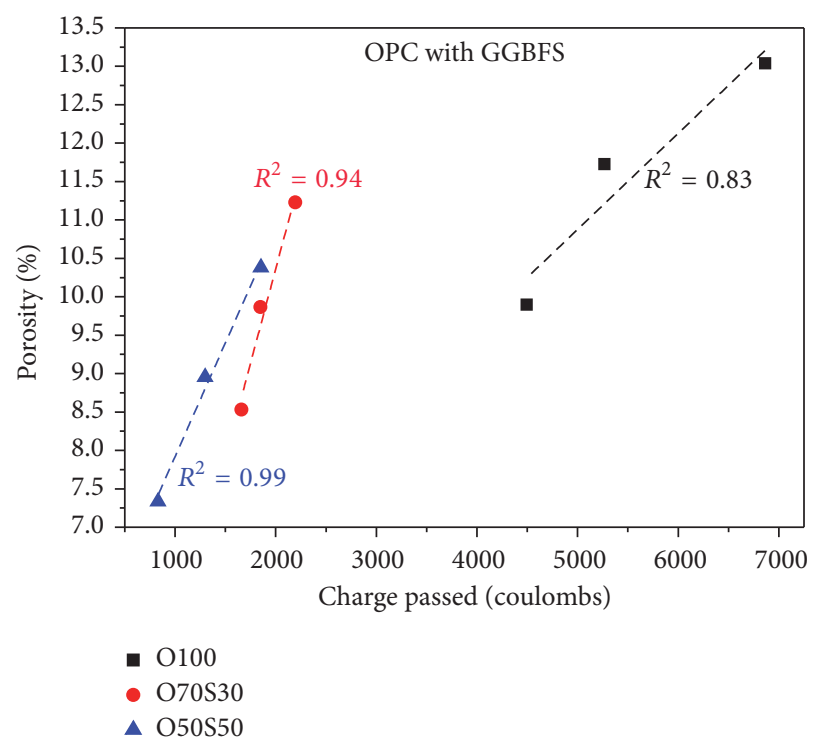

(a)

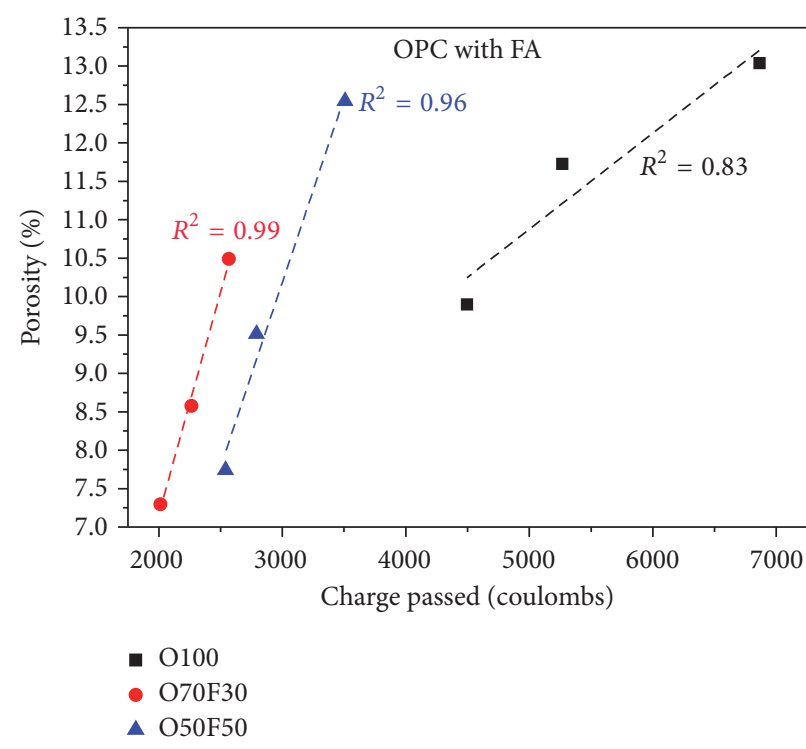

(b)

FIGURE 9: Correlation graph between charge passed coulomb versus porosity: (a) GGBFS in HPC and (b) FA in HPC.

TABLE 5: Constants " $a$ " and " $b$ " and regressions coefficients $R^{2}$.

\begin{tabular}{|c|c|c|c|c|c|c|c|c|c|}
\hline \multirow{3}{*}{ System } & \multicolumn{9}{|c|}{ Correlation } \\
\hline & \multicolumn{3}{|c|}{$\mathrm{CPC}$ versus $\mathrm{CS}$} & \multicolumn{3}{|c|}{$\mathrm{CPC}$ versus $\mathrm{CDC}$} & \multicolumn{3}{|c|}{$\mathrm{CPC}$ versus $\mathrm{P}$} \\
\hline & $a$ & $\begin{array}{c}b \\
\times 10^{-2}\end{array}$ & $R^{2}$ & $\begin{array}{c}a \\
10^{-12}\end{array}$ & $\begin{array}{c}b \\
10^{-15} \\
\end{array}$ & $R^{2}$ & $a$ & $\begin{array}{c}b \\
\times 10^{-2}\end{array}$ & $R^{2}$ \\
\hline $\mathrm{O} 100$ & 69 & 0.532 & 0.96 & 3.09 & 2.08 & 0.91 & 4.62 & 0.13 & 0.83 \\
\hline O70S30 & 76 & 1.72 & 0.97 & 0.68 & 2.67 & 0.96 & 0.56 & 0.49 & 0.94 \\
\hline O50S50 & 57 & 0.93 & 0.98 & 0.29 & 3.02 & 0.99 & 0.49 & 0.29 & 0.99 \\
\hline O70F30 & 79 & 1.6 & 0.98 & 1.09 & 2.51 & 0.99 & 4.40 & 0.58 & 0.99 \\
\hline O50F50 & 71 & 1.16 & 0.96 & 3.46 & 1.61 & 0.96 & 4.21 & 0.48 & 0.96 \\
\hline
\end{tabular}

(2) Better chloride diffusion resistance properties are observed for 50\% GGBFS, and 30\% FA in HPC with $0.37 w / b$ ratio of concrete showing minimum value. The effective porosity values are decreased as follows: 9.89\% for HPC, $7.30 \%$ for $30 \%$ FA in HPC, and 7.33\% for $50 \%$ GGBFS in HPC. Similarly, chloride diffusion coefficient also follows the same trend: $1.2053 \times$ $10^{-11}$ for HPC, $0.6137 \times 10^{-11}$ for $30 \% \mathrm{FA}$ in HPC, and $0.2916 \times 10^{-11}$ for $50 \%$ GGBFS in HPC. These results conclude the excellent durability performance in HPC containing FA and GGBFS.

(3) Among 15 mixes of concrete, 30\% FA and 50\% GGBFS in HPC with $0.37 w / b$ ratio show the least pores, minimum current flow, and less chloride diffusion coefficient. This study indicates that better durability performance for chloride environment is obtained in HPC containing GGBFS and FA compared to a control mix.

(4) Through regression analysis, several durability performances such as compressive strength, diffusion coefficient, and porosity are compared with charge passed from RCPT results. They have high determination coefficient over 0.85 for all the cases, which indicates that electrical charge from RCPT can be another index for both durability and structural performance.

\section{Conflicts of Interest}

The authors declare that there are no conflicts of interest regarding the publication of this paper.

\section{Acknowledgments}

This research was supported by Basic Science Research Program through the National Research Foundation of Korea (NRF) funded by the Ministry of Science, ICT \& Future Planning (no. 2015R1A5A1037548) and Basic Science Research Program through the National Research Foundation of Korea (NRF) funded by the Ministry of Education (NRF2016R1D1A1A09919224). 


\section{References}

[1] B. Lomborg, The Skeptical Environmentalist: Measuring the Real State of the World, Cambridge University Press, Cambridge, UK, 2001.

[2] X. Shi, N. Xie, K. Fortune, and J. Gong, "Durability of steel reinforced concrete in chloride environments: an overview," Construction and Building Materials, vol. 30, pp. 125-138, 2012.

[3] G. Horrigmoe, "Future needs in concrete repair technology," in Proceedings of the Concrete Technology for a Sustainable Development in the 21st Century, E\&FN Spon, London, UK, 2000.

[4] L. Bertolini, B. Elsener, P. Pedeferri, and R. Polder, Corrosion of Steel in Concrete: Prevention, Diagnosis, Repair, Wiley-VCH, Weinheim, Germany, 2004.

[5] C. L. Page, "Nature and properties of concrete in relation to reinforcement corrosion," in Proceedings of the Corrosion of Steel in Concrete, Aachen, Germany, 1992.

[6] T. H. Wee, A. K. Suryavanshi, and S. S. Tin, "Evaluation of rapid chloride permeability test (RCPT) results for concrete containing mineral admixtures," ACI Structural Journal, vol. 97, no. 2, pp. 221-232, 2000.

[7] U. Angst, B. Elsener, A. Jamali, and B. Adey, "Concrete cover cracking owing to reinforcement corrosion-theoretical considerations and practical experience," Materials and Corrosion, vol. 63, no. 12, pp. 1069-1077, 2012.

[8] L. Samples and J. Ramirez, "Methods of corrosion protection and durability of concrete bridge decks reinforced with epoxycoated bars phase I," Tech. Rep. FHWA/IN/JTRP-98/15, Purdue University, West Lafayette, Ind, USA, 1999.

[9] C. Christodoulou, G. Glass, J. Webb, S. Austin, and C. Goodier, "Assessing the long term benefits of impressed current cathodic protection," Corrosion Science, vol. 52, no. 8, pp. 2671-2679, 2010.

[10] V. Saraswathy and H.-W. Song, "Improving the durability of concrete by using inhibitors," Building and Environment, vol. 42, no. 1, pp. 464-472, 2007.

[11] V. Saraswathy and H.-W. Song, "Corrosion performance of rice husk ash blended concrete," Construction and Building Materials, vol. 21, no. 8, pp. 1779-1784, 2007.

[12] S. Muralidharan, V. Saraswathy, S. P. M. Nima, and N. Palaniswamy, "Evaluation of a composite corrosion inhibiting admixtures and its performance in Portland pozzolana cement," Materials Chemistry and Physics, vol. 86, no. 2-3, pp. 298-306, 2004.

[13] H.-W. Song and V. Saraswathy, "Analysis of corrosion resistance behavior of inhibitors in concrete using electrochemical techniques," Metals and Materials International, vol. 12, no. 4, pp. 323-329, 2006.

[14] S. P. Karthick, A. Madhavamayandi, S. Muralidharan, and V. Saraswathy, "Electrochemical process to improve the durability of concrete structures," Journal of Building Engineering, vol. 7, pp. 273-280, 2016.

[15] S. Bhaskar, B. Ravindra Gettu, H. Bharatkumar, and M. Neelamegam, "Strength, bond and durability related properties of concretes with mineral admixtures," Indian Concrete Journal, vol. 86, no. 2, pp. 9-16, 2012.

[16] X.-Y. Wang and K.-B. Park, "Analysis of compressive strength development of concrete containing high volume fly ash," Construction and Building Materials, vol. 98, pp. 810-819, 2015.

[17] B. S. Divsholi, T. Y. D. Lim, and S. Teng, "Durability properties and microstructure of ground granulated blast furnace slag cement concrete," International Journal of Concrete Structures and Materials, vol. 8, no. 2, pp. 157-164, 2014.

[18] P. Kathirvel, V. Saraswathy, S. P. Karthik, and A. S. S. Sekar, "Strength and durability properties of quaternary cement concrete made with fly ash, rice husk ash and limestone powder," Arabian Journal for Science and Engineering, vol. 38, no. 3, pp. 589-598, 2013.

[19] T. H. Kim, S. H. Tae, C. U. Chae, and W. Y. Choi, "The environmental impact and cost analysis of concrete mixing blast furnace slag containing titanium gypsum and sludge in South Korea," Sustainability, vol. 8, no. 6, pp. 502-520, 2016.

[20] Technical Report, "Korea Ground Granulated Furnace Slag Association, Seoul, South Korea," 2015, http://www.kslag.or .kr/site/.

[21] H. Zhao, W. Sun, X. Wu, and B. Gao, "The properties of the selfcompacting concrete with fly ash and ground granulated blast furnace slag mineral admixtures," Journal of Cleaner Production, vol. 95, pp. 66-74, 2015.

[22] M. Ondova, N. Stevulova, and E. Zelenakova, "Energy savings and environmental benefits of fly ash utilization as partial cement replacement in the process of pavement building," Chemical Engineering Transactions, vol. 25, pp. 297-302, 2011.

[23] P. Sulapha, F. S. Wong, H. T. Wee, and S. Swaddi wudhipong, "Carbonation of concrete containing mineral admixtures," Journal of Materials in Civil Engineering, vol. 15, no. 2, pp. 135-143, 2003.

[24] E. Güneyisi, M. Gesoglu, and E. Özbay, "Evaluating and forecasting the initial and final setting times of self-compacting concretes containing mineral admixtures by neural network," Materials and Structures, vol. 42, no. 4, pp. 469-484, 2009.

[25] M. Uysal, K. Yilmaz, and M. Ipek, "The effect of mineral admixtures on mechanical properties, chloride ion permeability and impermeability of self-compacting concrete," Construction and Building Materials, vol. 27, no. 1, pp. 263-270, 2012.

[26] H. Siad, A. H. Mesbah, H. Khelafi, K. S. Bernard, and M. Mouli, "Effect of mineral admixture on resistance to sulphuric and hydrochloric acid attacks in self-compacting concrete," Canadian Journal of Civil Engineering, vol. 37, no. 3, pp. 441449, 2010.

[27] S. C. K. Bendapudi, "Contribution of fly ash to the properties of mortar and concrete," International Journal of Earth Science Engineering, vol. 4, no. 6, pp. 1017-1023, 2011.

[28] L. J. Malvar and L. R. Lenke, "Efficiency of fly ash in mitigating alkali-silica reaction based on chemical composition," ACI Materials Journal, vol. 103, no. 5, pp. 319-326, 2006.

[29] F. U. A. Shaikh and S. W. M. Supit, "Compressive strength and durability properties of high volume fly ash (HVFA) concretes containing ultrafine fly ash (UFFA)," Construction and Building Materials, vol. 82, pp. 192-205, 2015.

[30] Q. Yuan, C. Shi, G. De Schutter, K. Audenaert, and D. Deng, "Chloride binding of cement-based materials subjected to external chloride environment-a review," Construction and Building Materials, vol. 23, no. 1, pp. 1-13, 2009.

[31] M. Nagesh and B. Bishwajit, "Modeling of chloride diffusion in concrete and determination of diffusion coefficients," ACI Materials Journal, vol. 95, no. 2, pp. 113-120, 1998.

[32] L. Tang, Chloride transport in concrete: measurement and prediction [Ph.D. thesis], Department of Building Materials, Chalmers University of Technology, Gothenburg, Sweden, 1996.

[33] T. Luping and L.-O. Nilsson, "Chloride binding capacity and binding isotherms of OPC pastes and mortars," Cement and Concrete Research, vol. 23, no. 2, pp. 247-253, 1993. 
[34] K. Maekawa, T. Ishida, and T. Kishi, "Multi-scale modeling of concrete performance," Journal of Advanced Concrete Technology, vol. 1, no. 2, pp. 91-126, 2003.

[35] H. W. Song, S. J. Back, C. H. Lee, and S. J. Kwon, "Service life prediction of concrete structures under marine environment considering coupled deterioration," Restoration of Buildings and Monuments, vol. 12, no. 2, pp. 265-284, 2006.

[36] H.-W. Song, J.-C. Jang, V. Saraswathy, and K.-J. Byun, "An estimation of the diffusivity of silica fume concrete," Building and Environment, vol. 42, no. 3, pp. 1358-1367, 2007.

[37] T. Ishida and K. Maekawa, "Modeling of durability performance of cementitious materials and structures based on thermohygro physics," in Proceedings of the 2nd International Workshop on Life Prediction and Aging Management of Concrete Structures (RILEM PRO 29), pp. 39-49, Paris, France, 2003.

[38] ASTM, "Standard test method for electrical indication of concrete's ability to resist chloride ion penetration," ASTM-C 1202, 2012.

[39] ASTM-C39, "Standard Test Method for Compressive Strength of Cylindrical Concrete Specimens," 2012.

[40] N. S. Berke and M. C. Hicks, "The life cycle of reinforced concrete decks and marine piles using laboratory diffusion and corrosion data," in Corrosion Forms and Control of Infrastructure, V. Chaker, Ed., ASTM STP-1137, pp. 207-231, American Society for Testing and Materials, Philadelphia, Pa, USA, 1992.

[41] L. Tang and L. O. Nilsson, "Rapid determination of the chloride diffusivity in concrete by applying an electrical field," $A C I$ Materials Journal, vol. 89, no. 1, pp. 49-53, 1992.

[42] N. Otsuki, S. Nagataki, and K. Nakashita, "Evaluation of $\mathrm{AgNO}_{3}$ solution spray method for measurement of chloride penetration into hardened cementitious matrix materials," ACI Materials Journal, vol. 89, no. 6, pp. 587-592, 1992.

[43] H.-W. Song and S.-J. Kwon, "Evaluation of chloride penetration in high performance concrete using neural network algorithm and micro pore structure," Cement and Concrete Research, vol. 39, no. 9, pp. 814-824, 2009.

[44] ASTM, "Standard test for determination of pore volume distribution of soil and rock by MIP," ASTM-D 4404, 2004.

[45] B. Tripathi, A. Misra, and S. Chaudhary, "Strength and abrasion characteristics of ISF slag concrete," Journal of Materials in Civil Engineering, vol. 25, no. 11, pp. 1611-1618, 2013.

[46] G.-F. Peng, N.-Q. Feng, and Q.-M. Song, "Influence of chlorideion adsorption agent on chloride ions in concrete and mortar," Materials, vol. 7, no. 5, pp. 3415-3426, 2014.

[47] H. Justnes, "A review of chloride binding in cementitious systems," Nordic Concrete Research, vol. 21, pp. 48-63, 1998.

[48] M. Maslehuddin, C. L. Page, and Rasheeduzzafar, "Temperature effect on the pore solution chemistry in contaminated cements," Magazine of Concrete Research, vol. 49, no. 178, pp. 135-145, 1997.

[49] O. S. B. Al-Amoudi, M. Maslehuddin, and M. A. Bader, "Characteristics of silica fume concrete and its impacts on concrete in the Arabian Gulf," Concrete, vol. 35, no. 2, pp. 45-50, 2001.

[50] O. S. B. Amoudi, M. Rasheeduzzafar, Maslehuddin, and A. I. AlMana, "Prediction of longterm corrosion resistance of plain and blended cement concretes," ACI Materials Journal, vol. 90, no. 6, pp. 564-570, 1993.

[51] O. S. B. Al-Amoudi, W. A. Al-Kutti, S. Ahmad, and M. Maslehuddin, "Correlation between compressive strength and certain durability indices of plain and blended cement concretes," Cement and Concrete Composites, vol. 31, no. 9, pp. 672-676, 2009.
[52] D. C. Montgomery and E. A. Peck, Introduction to Linear Regression Analysis, John Wiley \& Sons, New York, NY, USA, 1982. 

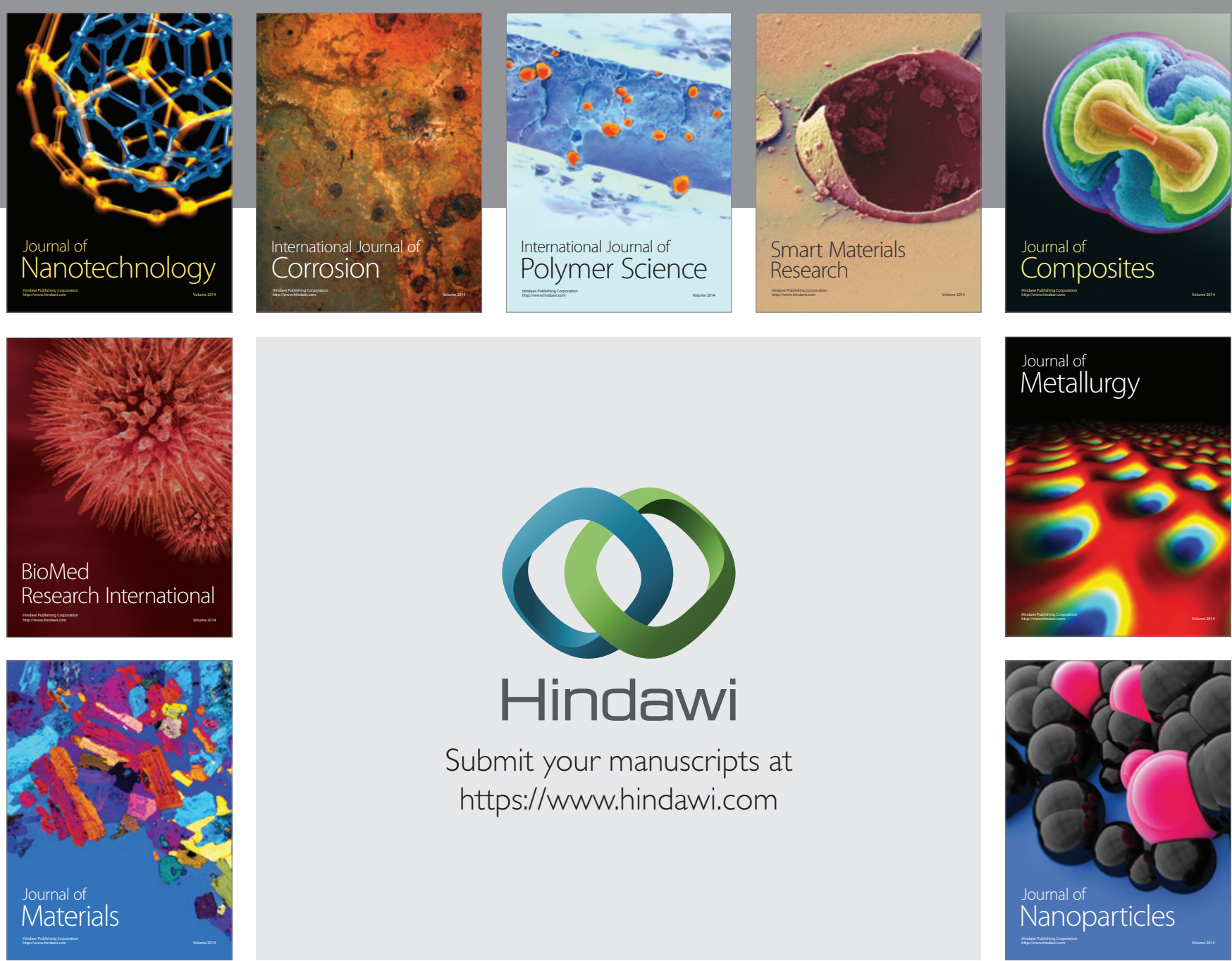

\section{Hindawi}

Submit your manuscripts at

https://www.hindawi.com

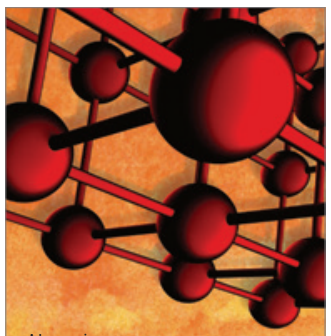

Materials Science and Engineering
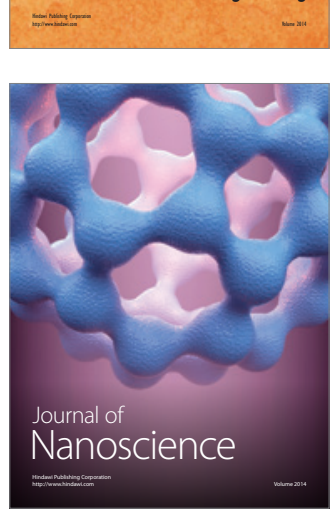
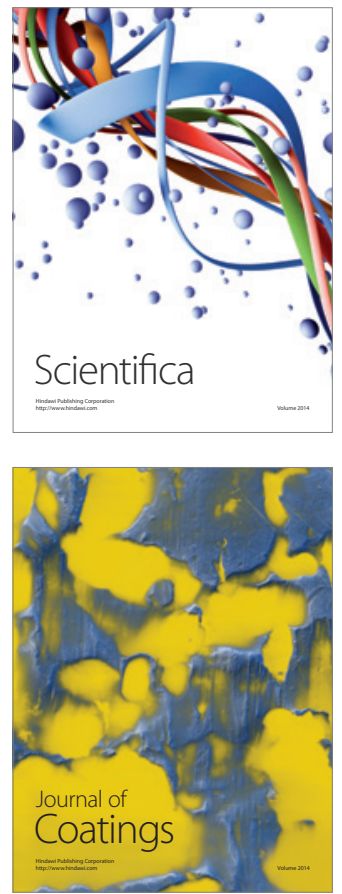
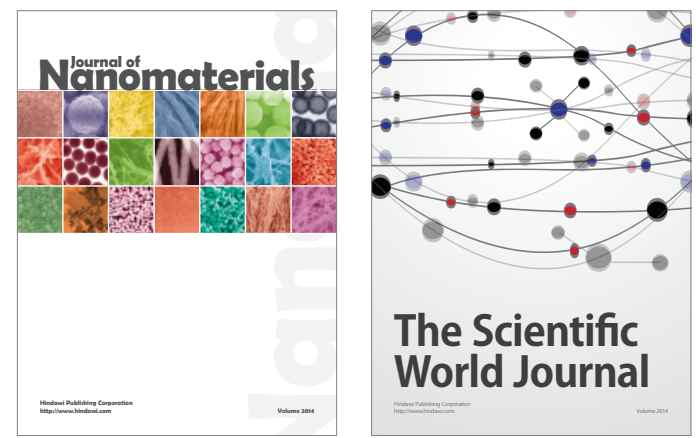

The Scientific World Journal
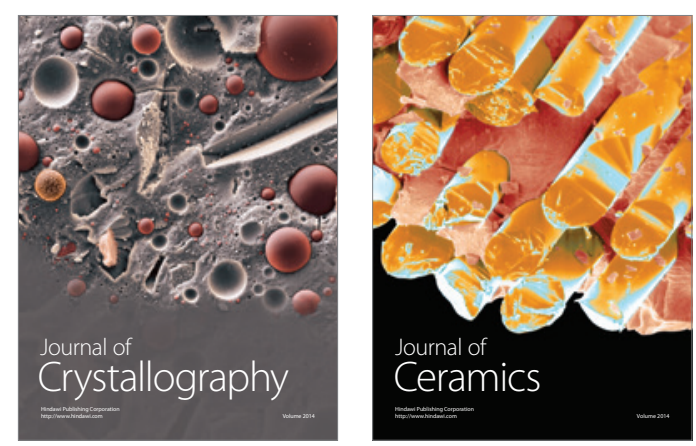
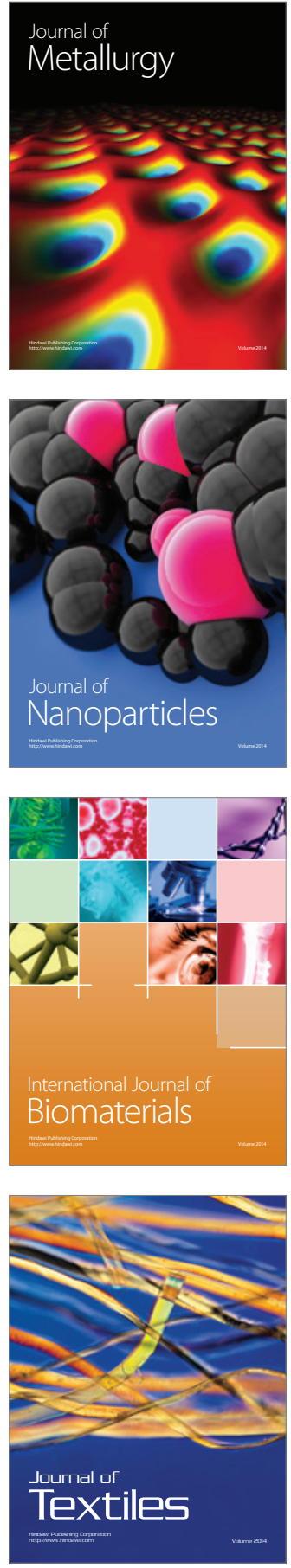